\title{
Issues and Strategies for the Conservation of the Artificial Water System in Hongcun, China
}

\author{
Tingshen $\mathrm{Li}^{1,1}$ \\ ${ }^{1}$ Politecnico di Milano, DASTU - dpt. of Architecture and Urban Studies, 20133, Milan, Italy
}

\begin{abstract}
Since 2012, the Chinese Government has proposed the preservation concept of the "Traditional Village" in order to conserve the heritage of historic centres at the village-scale throughout China, which are being profoundly influenced by modernization. However, subject to the limitations of awareness levels, the conservation of the "Traditional Village" only focuses on the historic buildings within the Historic Centre and, there is a lack of focus on equally valuable cultural landscapes, open spaces and environments. Hongcun Traditional Village has been chosen as the case study of this paper and focuses on the conservation of its remarkable artificial water systems. The paper discusses the impacts and issues caused by the local conservation policies and practical interventions on Hongcun's artificial water system over the last 20 years. The paper concludes by proposing a provisional methodological approach and treatment solutions for the conservation of Hongcun's artificial water system, which is largely based on learning from European experiences.
\end{abstract}

\section{Introduction}

In China, the preservation of Historic Centres is reflected in different forms and scales such as the "Famous Historical and Cultural Cities, Districts, Towns and Villages". Since 1982 the "Famous Historical and Cultural Cities" act was proposed as a preservation concept by Hou Renzhi of Peking University, Zheng Xiaozheng of the Ministry of Construction and Shan Shiyuan of the Palace Museum. Through its development and evolution, the "Famous Historical and Cultural Cities" became the preservation mechanism of the historical and cultural heritage related to the administrative jurisdiction of the government [1] and gradually expanded in scope to become the "Famous Historical and Cultural Cities, Districts, Towns and Villages". Since the new preservation mechanism category "Traditional Village" was proposed in 2012, the specific preservation and conservation of small historic centres has only just begun in China. However, there are more than three million existing natural villages in China. Therefore, determining the development and mechanism of the preservation and conservation of Historic Centres in China is the fundamental study for the preservation of small historic centres.

\footnotetext{
${ }^{1}$ Corresponding author: litingshen1988@gmail.com
} 
The preservation area and the specific conservation contents have been determined in the "Conservation Planning" of historic centres with different scopes [2: 12], which in practice has established the theory and technical standards for conservation levels, objects, principles and methods [3]. However, unlike the detailed regulations for the built heritage within the historic centre, the conservation regulations for the built environment are very superficial and perfunctory, which causes problems in the realization of policies and practices. Therefore, this paper attempts to explore the issues of conservation policies and practices of the built environment through the case of the Hongcun Traditional Village.

\section{Specific regulations "conservation planning" as related to the conservation of the built environment}

The preservation of the historic centre should not only aim to conserve just the built heritage within the historic centre, but the historical elements of the built environment beyond the centre should also be included in the scope of conservation. However, the context related to the conservation of the built environment within the historic centre is not always given proper attention. Since the Requirements for the Conservation Planning of Famous Historical and Cultural City 1994 were issued, the contents for the built environment have been simply presented as "preserving the integrated environments", and focused primarily on the conservation of several monuments.

In 2005, the Code of Conservation Planning for Historic Cities (GB50357-2005) [4] initially defined the principle of "preserving the historical environment", and in Section 2 Terminology, defines and explains the term of "Townscape" and "Historic Environment Element". Meanwhile, the contents delineated in the scope of preservation also include "the conservation of cultural relics, protected buildings, historical buildings and historic environment elements in historic conservation areas" and the preparation of the "Conservation Planning" which contains the "maintenance of the building (structure) and historic environment elements". However, as to how to conserve the "Historic Environment Element", the Code 2005 does not mention relevant references and practices.

The Requirements for the Conservation Planning of Famous Historical and Cultural Cities, Towns and Village 2012 (Trial) [5] are inherited from the partial definition and contents from the Code 2005. The Requirements 2012 also define the main object as preserving the "Historic Environment Element" and the necessity to investigate the "traditional patterns, historical features and historic environment element". More importantly, Requirements 2012 first defines that the preparation of the "Conservation Planning" should propose the conservation measures for the "landscape environment such as topography, rivers and lakes, farmland, landscapes, and natural ecology" that are closely related to the historic centre. In spite of these increased concerns, the treatments of the built environment are still less clear than that for built heritage, which is required to be included in analysis charts and graphics in the "Conservation Planning". However, there are no evident specifications for the built environment, which indicates that the conservation measures for the built environment are not developed enough by the national regulation for "Conservation Planning". 


\section{Case Study: Conservation of the Artificial Water System of Hongcun Traditional Village}

Hongcun is a traditional village in Yi County, Southern Anhui Province, China, established in 1131 and contains over 870 years of history in an area of 19.11 hectares. Hongcun lies at the southern foot of Lei Gang Hill, is crossed by the Xixi Brook and faces the South Lake to its south, which conforms to the Feng Shui Principle that requires "embracing the masculine and positive and gathering the energy of life from nature" [6]. The particular local features of the traditional dwellings, the singular water system and the exquisite carvings make Hongcun outstanding in China. Together with Xidi Traditional Village ${ }^{2}$, Hongcun was added to the World Heritage List by UNESCO in 2000 [7].

The two traditional villages of Xidi and Hongcun preserve to a remarkable extent the appearance of non-urban settlements of a type that largely disappeared or was transformed during the last century. Their street plan, their architecture and decoration, and the integration of houses with comprehensive water systems are unique surviving examples [8: 65].

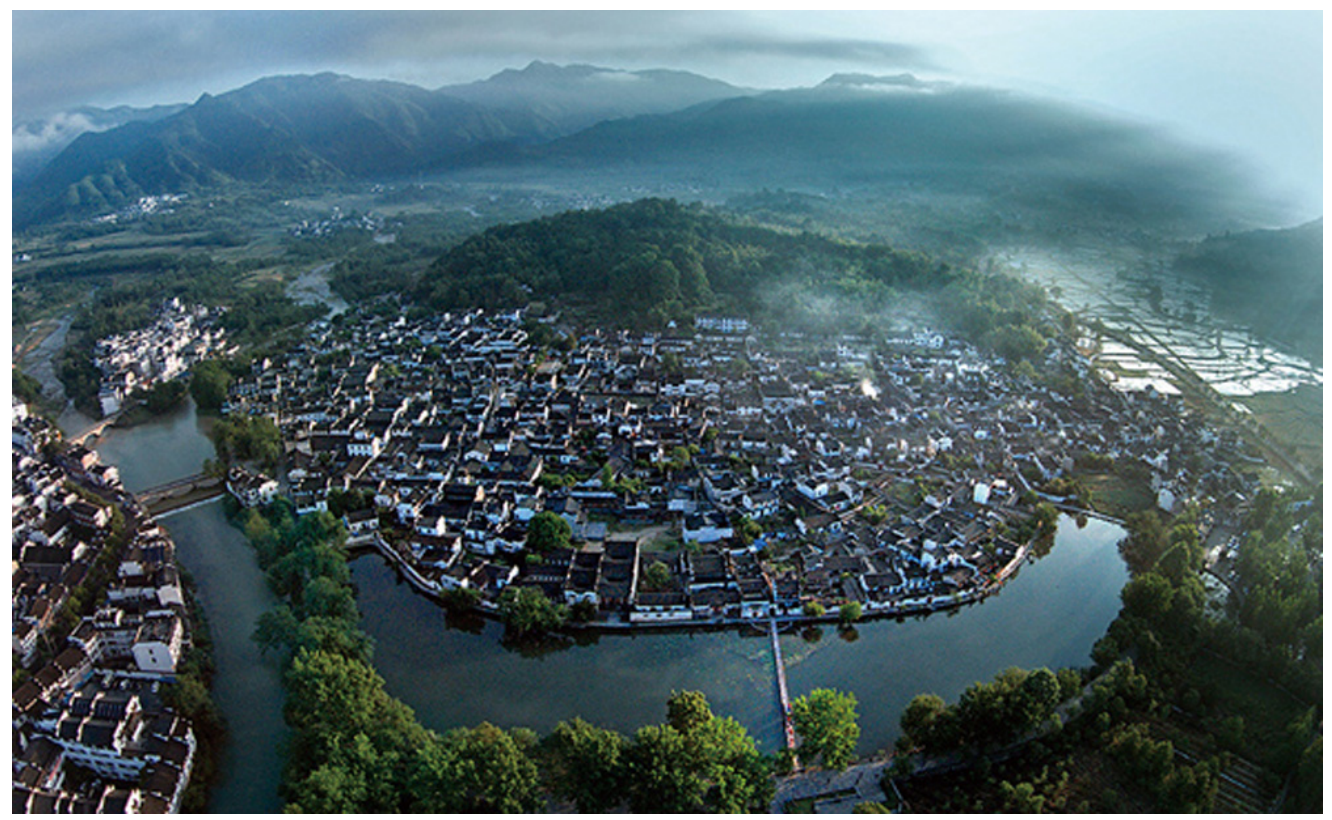

Fig. 1. Integrated appearance of Hongcun with the relationship of environment

Source: Official website of Yi County http://www.yixian.gov.cn/

Unquestionably, UNESCO recognizes the integrated appearance of Hongcun and Xidi in their decision to include them on the World Heritage List (Fig. 1). Compared with Xidi,

\footnotetext{
${ }^{2}$ Xidi Traditional Village was established in 1047, which is also located in Yi County and is about $19 \mathrm{~km}$ away from Hongcun. There are three ancestral halls and one memorial archway, as well as 224 ancient residential buildings with 122 of them being well preserved. All of these were built between the $14^{\text {th }}$ and $19^{\text {th }}$ century. Situated at the foot of the mountains and facing rivers and lakes, Xidi merges harmoniously with nature. Most traditional dwellings are built on the streams, therefore having close affinity to water. 1,5 kilometres west of Xidi where two mountain ridges converge, a water mouth garden was built in accordance with the Feng Shui Principle, together with a few academies [6].
} 
Hongcun has a greater relationship with its environment and the most prominent built element is the artificial water system with a history of more than 400 years. This system includes the Yi Xi River inlet, Shui Zhen, Moon Pond, South Lake and the household pond, which is the main element of Hongcun planning, production, life, drainage, prevention and improvement of the ecological environment. For Hongcun, it is necessary to conserve the remarkable built environment. Nevertheless, conserving the artificial water system of Hongcun has not been given enough attention. There are many practical reasons for this phenomenon, but undoubtedly, the direction and guidance emerging from local conservation policies, resulting in the lack of conservation of the artificial water system are the main issues worthy of analysis and discussion.

\section{Hongcun's Local Policies on the Conservation of the Artificial Water System}

As mentioned above, the formulation and implementation of conservation policies in China's historic centres is reflected in local conservation planning, with Hongcun Traditional Village being no exception. Up to now, there have been four versions of the conservation planning of Hongcun, but the Conservation Plan 1989 was a premature exploratory conservation document for Hongcun, consequently, its content is quite simple and superficial without much reference value. However, the Conservation Plan 1999 began to consider, in simple way, the treatment of the artificial water system as an improvement to the village's infrastructure. Subsequently, the Conservation Plan 2006 emphasizes the conservation of the built environment and puts forward specific conservation measures necessary for the artificial water system for the first time. Nevertheless, the conservation measures are still too generic and simple, seeming more like glossaries rather than specific conservation measures. For instance, the conservation of the artificial water system instructs to "Maintain the pattern of combination and the scale changes with water and alley system", which does not contain any reference to the practical conservation of the artificial water system of Hongcun.

In September 2012, the Index System of Traditional Village Evaluation Identified (Trial) [5] was issued by four Ministries ${ }^{3}$ and Hongcun was selected as the first batch. According to the specification of the Index System 2012, the Conservation Planning of Hongcun Village, Yi County 2016-2030 was issued and implemented in 2016. For the conservation of the built environment, this Conservation Plan 2016 provides specifically the submissions and descriptions of Site Selection (Site Environment, Shui Kou Garden and Pastoral landscape), Artificial Water System (Shui Zhen, Moon Pond and South Lake), Alleys Space and Other Historical Environmental Elements (36 Ancient Wells, 95 Ancient flagstones, 1 Ancient Bridge and 2 Ancient trees), which certifies the built environment of Hongcun in a more detailed way compared with the previous conservation planning. Meanwhile, the conservation measures for the artificial water system are proposed for the first time:

- $\quad$ Shui Zhen: The existing Hongcun full 1200 meters Shui Zhen full dredging and maintenance, and rehabilitation of the disappeared 1400 meters.

- $\quad$ Moon Pond: Dredging every two years to strengthen the maintenance.

- South Lake: Full dredging in 2006 but still with serious problems. The lake embankment damaged seriously. Dredging should be two years, and timely repair lake embankment.

\footnotetext{
${ }^{3}$ The four Ministries specifically are the Ministry of Housing and Urban-Rural Development, Ministry of Culture and Tourism, Ministry of Finance and State Administration of Cultural Heritage.
} 
Despite the corresponding conservation measures proposed, the relevant contents of the Conservation Plan 2016 are relatively conventional and do not conduct a comprehensive investigation and inspection on the present status of the artificial water system, yet still put forward specific conservation measures. In fact, there are many problems facing the artificial water system of Hongcun and its conservation status is not very satisfactory. The following sections will discuss the actual situation.

\section{Hongcun's Practical Interventions on the Artificial Water System}

The significance of Hongcun's artificial water system to the Hongcun's heritages goes without saying. At present, the Hongcun government has taken a series of maintenance, including dredging of Shui zhen, Moon Pond and South Lake, maintaining shore barges, regularly retrieving the garbage and so on (Fig. 2). And also, management policies have strictly forbidden carrying out any form of renovation and destruction of Shui Zhen. At the same time, the source of artificial water system is from the Xixi Brook, and now this is strictly protected to ensure the artificial water system runs unobstructed and clear.

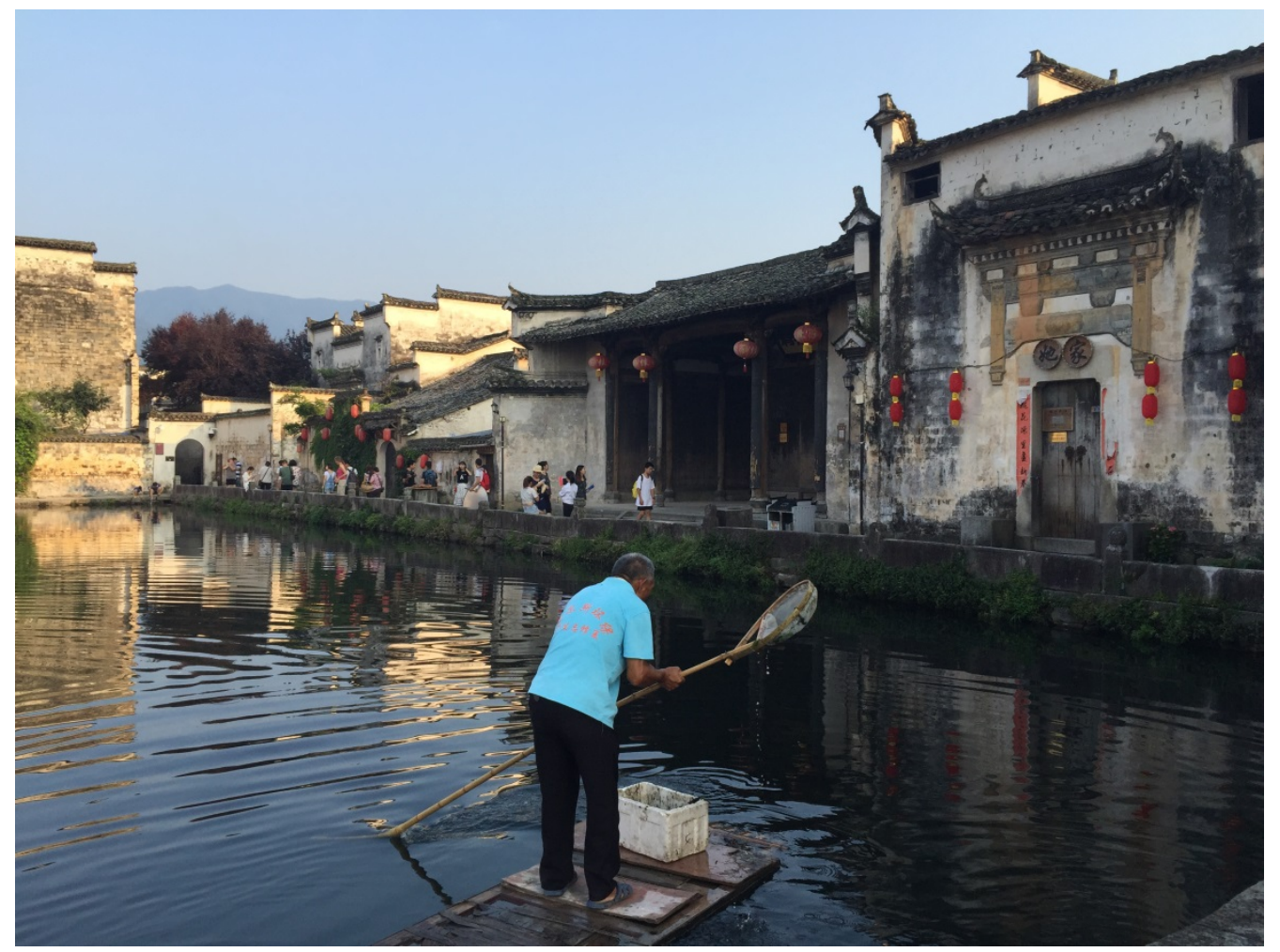

Fig. 2. The worker is clearing fallen leaves and garage on the Moon Pond, but there is no further intervention for the Moon Pond. Source: the author, 2017.

Although much attention has been paid to the treatment of the artificial water systems of Hongcun, some problems were identified during the investigation. For instance, the interventions for the South Lake that are mentioned in the Conservation Plan 2016 have not yet been completed as of this investigation, which comprises many parts of the embankment of the South Lake and the Moon Pond, have experienced a series of decay factors, such as biological colonization, erosion, missing parts of the 
embankment and other mechanical damage. Another issue is that the area of the Shui Zhen is far away from the main tourism area, where there is no direct impact on the overall water quality because there is no confluence with the South Lake. Finally, the actual situation of Shui Zhen in this area is also not satisfactory because there are more restaurants, hotels, cafés and other commercial activities near the area, so that the water quality of the Shui Zhen in this part has been polluted to some extent, as the shops discharge their waste water directly into the Shui Zhen. Additionally, some wires have been laid directly through Shui Zhen and the weeds and many wires hinder the water flow of the Shui Zhen, with one branch of Shui Zhen drying up (Fig. 3).

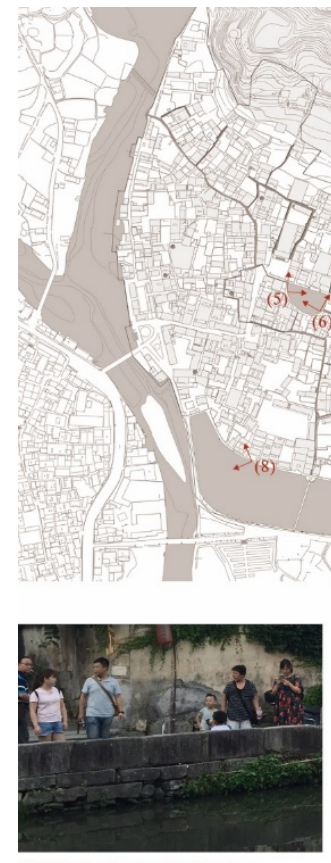

(5) Biological colonization

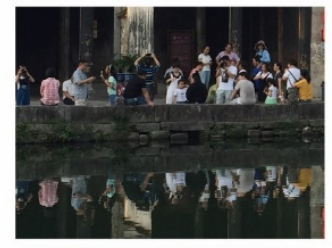

(6) Missing part of embankment

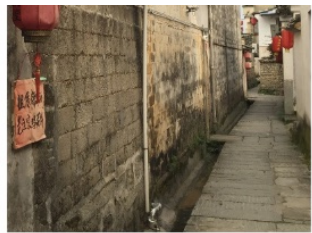

(1) Waste water into Shui Zhen

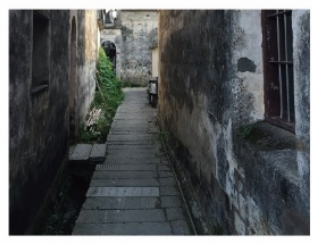

(3) Weeds hinder the Shui Zhen

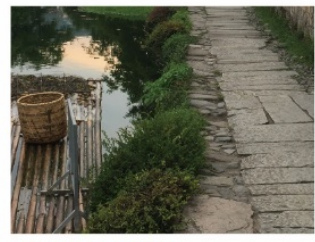

(7) Missing cobble

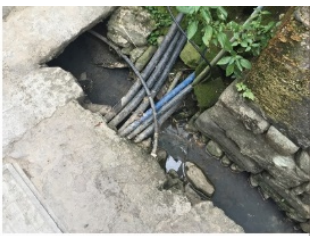

(2) Wires hinder the Shui Zhen

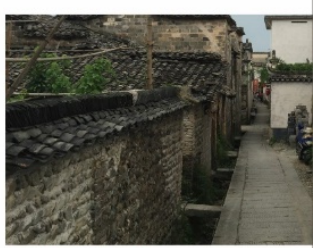

(4) Shui Zhen in Dry State

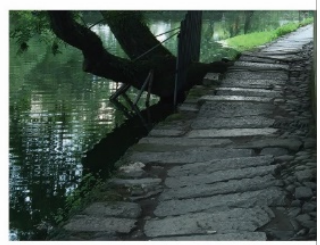

(8) Soil erosion of the embankment

Fig. 3. Present problems of the Artificial Water System within Hongcun. Source: the author.

For another example of the intervention, the government prevents the formation of stagnant water in the South Lake through water diversion, which is supposed to be a good intervention for the artificial water system, but the intervention measure was made too randomly. Mr. Wang Ruihua, a local scholar of Hongcun, has raised this issue during the investigation:

The remediation for the lake water is a good thing, but why cannot the government take a better and more environmentally friendly design? The scenery of South Lake is so beautiful, and suddenly appeared this ugly thing. In the 1980s, tourism was developed, and we can still build a new Hua Bridge which already became an important tourism point. But now the tourism revenue is increasing so much, but the government took the action so carelessly (Fig. 4).

Although the government has made many treatment and maintenance activities to the artificial water system of Hongcun, the effect is not very satisfactory in general. For its treatment, a scientific assessment and treatment measures to ensure that intervention measures for the active facilitation of the artificial water system are urgently needed. First of all, the contents of Hongcun's conservation plan are too simple for future conservation and treatment of the artificial water system. Additionally, the actual 
intervention measures do not intervene in accordance with the requirements of the conservation plan. At the same time, the artificial water system in all areas should be treated differently: cannot be all treated with different standards because its location is not in the core tourism area. Therefore, a methodological approach should be considered and discussed for the conservation of the artificial water system of Hongcun.

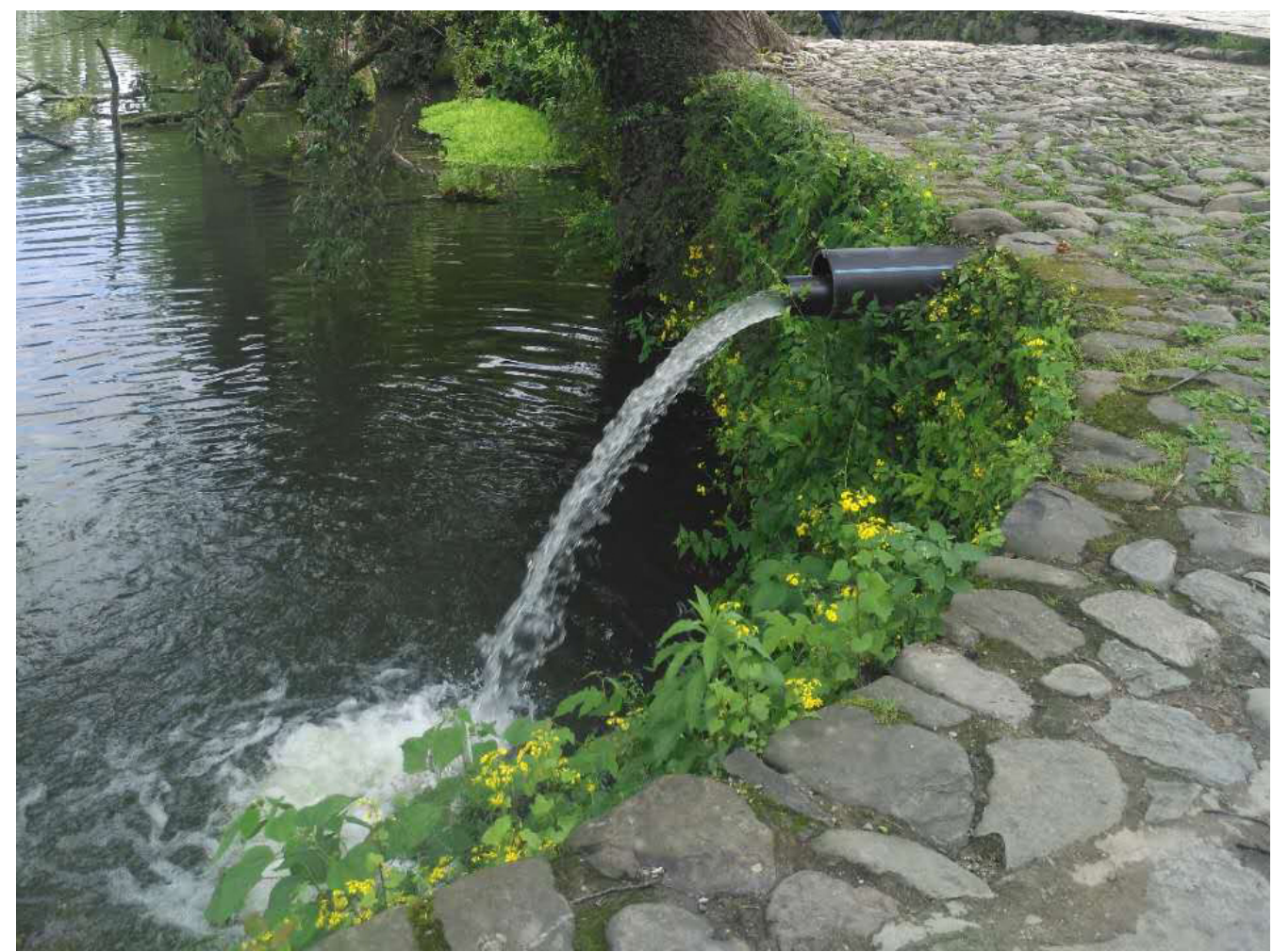

Fig. 4. Random Intervention Measure for preventing the formation of stagnant water. Source: the author, 2017.

\section{Methodological Approach to the Conservation of Hongcun's Artificial Water System}

After the discussions about the problems of Hongcun's artificial water system in the previous section, it is undoubtedly necessary to put forward specific conservation solutions for it. However, how to formulate appropriate and effective conservation measures respectively for the different aspects of the artificial water system is a difficult issue for Hongcun. The difficulty is also due in part to the fact that there is no clear measure or even enough attention in current Chinese academia on the treatment of built environments of traditional villages, not to mention the specific measures for landscape heritage and the technical innovation necessary for potential interventions. Consequently, what needs to be clarified is that without the appropriate scientific conservation measures to ensure the preservation of the authenticity of Hongcun's artificial water system, there will be tremendous and ongoing damage to its characteristic heritage. Nevertheless, what kind of methodological approach and 
appropriate and scientific conservation measures should be proposed for Hongcun's artificial water system?

Initially, conservation must not be the same for all aspects of the artificial water system, which means a more general treatment solution to the artificial water system of Hongcun will not work at all. The corresponding treatments should include the following measures: the restoration for the stone masonry of the embankment of the Shui Zhen, Moon Pond and South Lake, the dredging of the water flow and other treatment solutions, thus the corresponding treatment solutions must be put forward based on the relevant classification and the collected information for different elements of Hongcun's artificial water system to achieve ideal conservation results.

There is an awareness of conservation that should be first established, which is that the conservation of Hongcun's artificial water system should be given the same important awareness to that of the interventions on Hongcun's built heritage. Therefore, in order to understand the conservation mechanism of the different aspects of Hongcun's artificial water system, in particular the cause of decay and structural defects, as well as to find treatment solutions to restore the elements, and improve the durability of traditional techniques, the technical suggestions for the improvement of traditional techniques and the correct execution must be organized through adjustments to Hongcun's conservation policies as well as the specific conservation plans for the artificial water system [9]. Therefore, first, the constructive technique, the original materials and the causes of decay phenomena must be analysed and constituted to form the fundamental materials for future interventions. Only on the basis of the comprehensive collection of historic information, the knowledge of the traditional materials and proper construction techniques for every element of the artificial water system can the specific conservation measures be proposed for practical treatments.

Linee guida per la manutenzione dei terrazzamenti delle Cinque Terre

- Disposizione degli elementi lapidei:

-nella fondazione andranno disposte le pietre di maggiore dimensione che dovranno essere posizionate di punta

cercando di riempire il più possibile lo spazio di fondazione;

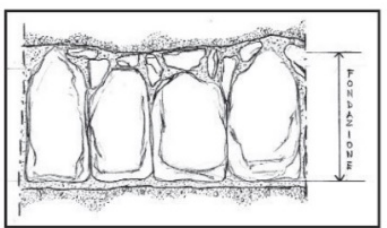

CORRETTO

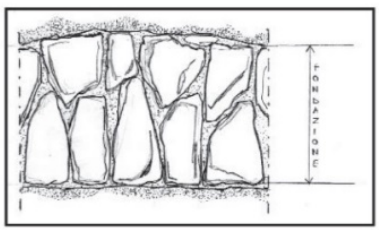

CORRETTO

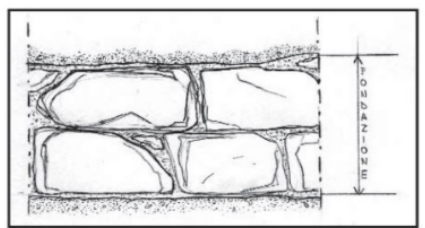

ERRATO

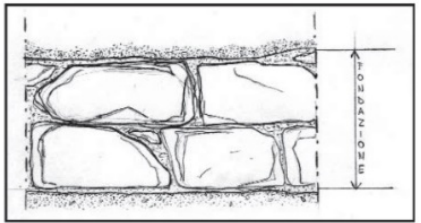

ERRATO

Fig. 5: Example of analysis and suggestions for the fill and place for the missing parts of the dry walls in the Cinque Terre [11: 53]. 
Afterward, the appropriate conservation measures for the elements of the artificial water system can be developed based on progressive measures, which are the Preparation (cleaning of the construction area and the detachment of the surface of the elements), Check (verification of the stability of the elements) and Realization (conservation measures adhere to continued use of the local and proper materials and techniques). It will also be necessary to obtain new material of the same nature as the one present or similar to it (Fig. 5). All the aspects proposed identify clearly the necessary steps and the conservation measures for the different elements of Hongcun's artificial water system [10].

So far, there have been no doubts that all the elements of Hongcun's artificial water system will eventually require maintenance. The treatment solutions could support territorial and town planning to conserve and enhance historical, cultural and natural landscape characteristics [12]. This methodological approach will be a change in the concept of the preservation and conservation of the environmental settings of Hongcun, which can only take place through a comprehensive and complete investigation campaign, the thoughtful analysis of the phenomena of decay and appropriate treatment solutions to ensure the authenticity of the built environment of Hongcun Traditional Village and other traditional villages in China.

\section{Acknowledgements}

This research was funded by the China Scholarship Council (CSC201406420029).

\section{Short Resume}

Tingshen Li, is a PhD candidate of Preservation of Architectural Heritage in the Department of Architecture and Urban Studies, Politecnico di Milano, Milan, Italy. His research interests focus on preservation and conservation of the architectural heritages, landscape heritage and traditional villages.

\section{References}

1. QIU, B.-X. 2012. "Situation, Problems and Countermeasures of the Preservation of the Famous Historical and Cultural Cities in China" [in Chinese], China Ancient City, $\mathrm{n}^{\circ}$ 12: 4-9.

2. LI, J. 2013. "Research on the Law System of China's Historical Cities Protection" [in Chinese], Master Thesis of Chongqing University.

3. LIN, L. 2016. "System Evolution and Introspection of the Conservation Planning for Chinese Famous Historical and Cultural Cities" [in Chinese], China Ancient City, $\mathrm{n}^{\circ}$ 8: 13-17.

4. MINISTRY OF CONSTRUCTION OF THE PEOPLE'S REPUBLIC OF CHINA; NATIONAL BUREAU OF QUALITY INSPECTION, 2005. Code of Conservation Planning for Historic Cities (GB50357-2005).

5. MINISTRY OF HOUSING, URBAN AND RURAL CONSTRUCTION; STATE ADMINISTRATION OF CULTURAL HERITAGE, 2012. Requirements for the Conservation Planning of Famous Historical and Cultural Cities, Towns and Village (Trial).

6. MOHURD (MINISTRY OF HOUSING AND URBAN-RURAL DEVELOPMENT, 
CHINA); SACH (STATE ADMINISTRATION OF CULTURAL HERITAGE, CHINA), 2000. Nomination of the Properties for Inclusion on the World Heritage List: Ancient Villages in Southern Anhui Xidi and Hongcun.

7. UNESCO, 2000. Ancient Villages in Southern Anhui: Xidi and Hongcun, (WHC nomination file).

Retrieved from https://whc.unesco.org/uploads/nominations/1002.pdf [available on 11 January 2019].

8. ICOMOS, 2000. "Anhui villages (China) - Advisory Body Evaluation $n^{\circ} 1002$ ", in WORLD HERITAGE CONVENTION; WORLD HERITAGE COMMITTEE, Evaluation on Cultural Properties, $\left(24^{\text {th }}\right.$ ordinary session, Cairns, Australia, 27 November - 2 December 2000), Paris, UNESCO: 63-65. Retrieved from https://www.icomos.org/images/DOCUMENTS/World_Heritage/Volumes_Evaluati on/EN_Volume_dévaluation_2000_COMPLET.pdf [available on 11 January 2019].

9. DE MARCO, L.; MUSSO, S.F. 2008. "Governing the Transformations of a Terraced Landscape: The Case of Cinque Terre National Park", in X. Casanovas (ed.), Mediterranean Rehabilitation Experiences (Technical Report, RehabiMed), Barcelona, Collegi d'Aparelladors i Arquitectes Tècnics de Barcelona: 67-74. Retrieved from http://openarchive.icomos.org/id/eprint/1399 [available on 11 January 2019].

10. MUSSO, S.F.; FRANCO, G.; GNONE, M. 2008. Architettura Rurale nel Parco del Beigua. Guida alla Manutenzione e al Recupero, Padova, Marsilio.

11. MARTINI, S.; PESCE, G.; DE FRANCHI, R. 2004. Manuale per la Costruzione dei Muri a Secco, n.p., Tipografia Ambrosiana. Retrieved from https://www.researchgate.net/publication/278036489_Manuale_per_la_costruzion e_dei_muri_a_secco [available on 11 January 2019].

12. BORIANI, M.; CAZZANI, A. 2005. "The Naviglio of Martesana: Preservation and Conservation Problems of a Rural and Urban Landscape", in F. Sangiorgi, P. Branduini (eds.), European Research and Action Network on Intra or Peri-Urban Agricultural Spaces, (Proceedings of the International Workshop, Palazzo Feltrinelli, Gargnano del Garda, 24-25 October 2005), Milan, Università degli Studi - Istituto di Ingegneria Agraria: 89-93. 